\title{
PENGEMBANGAN INKUBATOR KEWIRAUSAHAAN DI UNIVERSITAS MUHAMMADIYAH SURAKARTA
}

\author{
Suranto ${ }^{1}$, Muhtadi ${ }^{2}$,Kuswaji Dwi $P^{3}$, dan Totok Budi Santosa ${ }^{4}$ \\ ${ }^{1}$ Fakultas Teknik, ${ }^{2}$ Fakultas Farmasi, ${ }^{3}$ Fakultas Geografi,${ }^{4}$ Fakultas Ilmu Kesehatan \\ Universitas Muhammadiyah Surakarta
}

\begin{abstract}
Business Entrepreneurial Incubator Program (Inwabi) programmed for entrepreneurship aims to implement the role of science and technology for entrepreneurship for students at the University of Muhammadiyah Surakarta (UMS). Activities include: recognition, empowerment, improvement of hard and soft skills of students, mental construct of student entrepreneurship (entrepreneur soft skills), so that students are able to be creators of jobs (job creators) not only job seekers (job seekers). The target of the program Inwabi provide assistance to the 20 students in the field of new entrepreneurial small businesses and make at least $50 \%$ managed to independently manage their own businesses. Methods of community service Papiku in Inwabi include learning, training and empowerment using the concept of Project Based Learning (PBL), which contains models of mentoring, empowerment: doing, empowering, facilitating and evaluating. Besides PBL also uses Participatory Rural Appraisal (PRA) of potential exploration-based talent to produce and acquire prospective new entrepreneurs accordance talent / potential of each. Implementation conducted on students who are ready to become tenants, including students PKMK, students starting a new business that already have a business. Inwabi Papiku activities include direct entrepreneurial training and learning (doing), empowered (empowering), facilitated by (facilitating), and evaluated the problem constraints (evaluating) for three months. Implementation of assistance Papiku Inwabi carried out cooperation and synergy with the institutions Socialpreneur who have competence in their fields, namely (a) the Vocational School, supports hardware-based technology, training, learning and training, (b) Talents Center, to support the implementation of potential exploration entrepreneur based talent / potential, (c) Kemal Abda, an online shop is a community in the field of internet marketing. Tenant business group in Inwabi activities covering the fields of internet marketing online shop (11), the culinary field (3), in batik and fashion (2), the culinary field (4), the implementation is divided into seven stages. During the three months generated at least $50 \%$ independent of the number of 20 tenants, 10 students (tenant) became new entrepreneurs are well established, the rest is still to understand the importance of entrepreneurship and self-employment as a mental construct a selection of work for him to be more independent.
\end{abstract}

Kata kunci: pemberdayaan, wirausaha, mandiri, berkelanjutan. 


\section{PENDAHULUAN}

Peningkatan ekonomi masyarakat diharapkan mampu menekan angka pengangguran. Pengangguran masih menjadi permasalahan klasik yang akan menimbulkan permasalahan serius bagi perkembangan perekonomian suatu negara/ bangsa sehingga perlu dicarikan solusi melalui sinergi semua instansi dan lembaga pemerintah, dunia usaha dunia industri dan komponen masyarakat lain yang peduli. Data statistik menunjukkan pada tahun 2011 bahwa angka pengangguran masih sangat tinggi, mencapai 8,12 juta jiwa atau $6,80 \%$ dari jumlah angkatan kerja, menurun sedikit dibanding tahun 2010 yang berjumlah 8,59 juta jiwa. Sebagian dari pengangguran tersebut adalah lulusan perguruan tinggi yang berjumlah 13,35\% dari 8,2 juta lulusan diploma dan sarjana di Indonesia (BPS. 2011).

Terdapatnya jumlah pengangguran tersebut, termasuk lulusan perguruan tinggi dikarenakan berbagai faktor, diantaranya: (1) Sistem pembelajaran yang diterapkan di perguruan tinggi saat ini masih terfokus pada bagaimana menyiapkan para mahasiswa lebih cepat lulus dan mendapatkan pekerjaan, bukan lulusan yang siap menciptakan pekerjaan (job seekers) daripada membuka lapangan (job creators); (2) Masalah link and match antara lulusan perguruan tinggi dengan dunia kerja belum terbangun dengan baik, terdapat lulusan perguruan tinggi masih dianggap kurang sesuai dengan kebutuhan dunia kerja, terutama Dunia Usaha dan Dunia Industri (DUDI); (3) Terdapat pembinaan potensi mahasiswa selama di kampus lebih dominan mengembangkan aspek kognitif dan kecenderungan mahasiswa dalam kegiatan ekstra kampusnya lebih terfokus kepada halhal bidang politik daripada hal- hal bidang ekonomi atau kewirausahaan; (4) Dari sisi demand tenaga kerja, dunia usaha dan industri sebagai end user, daya serapnya hanya mencapai $10 \%$ sampai $15 \%$ lulusan, sehingga setiap tahun terjadi peningkatan jumlah angkatan kerja yang kurang terserap secara maksimal.

Universitas Muhammadiyah Surakarta (UMS) memiliki mahasiswa sekitar 34.000 pada tahun 2014 dan yang menekuni dunia wirausaha masih sangat kecil, mahasiswa yang memiliki usaha sekitar 300 mahasiswa. Hal ini didukung oleh hasil tracer studi pada tahun 2014, bahwa lulusan UMS sampai terhitung tahun 2012 menunjukkan dari 3.275 alumni hanya $57 \%$ alumni yang bekerja, sisanya: meneruskan studi S2, merawat anak dan keluarga atau tidak bekerja. Dari 57\% yang bekerja tersebut hanya $2 \%$ saja yang menggeluti bidang kewirausahaan. Sebanyak $98 \%$ alumni yang bekerja tersebut bekerja pada orang lain atau sebagai pegawai. Ironisnya, alumni yang bekerja sebagai pegawai tersebut yang memperoleh gaji di atas 1 juta rupiah per bulan hanyalah sebesar 30\%, sebagian besar bergaji di bawah 1 juta rupiah (Muhtadi, 2015).

Universitas Muhammadiyah Surakarta merupakan salah satu PTS terbesar di Jawa Tengah memiliki tantangan terbesar, diantaranya harus mampu menghasilkan lulusan berkualitas tinggi (berkompeten) sesuai bidang dan mampu bersaing di pasar kerja. Bahkan diharapkan bisa menciptakan lapangan kerja baru, sehingga mampu memberikan kontribusi bagi penyerapan tenaga kerja dan mengurangi masalah pengangguran.

Realitas banyaknya pengangguran dan prospek lulusan UMS tersebut, sebenarnya telah banyak mendapat perhatian dari beberapa elemen UMS, seperti dilakukan oleh para dosen dan mahasiswa, termasuk secara kelembagaan terdorong oleh program pemerintah, maupun inisiatif lembaga UMS untuk memberikan bekal tambahan dalam mengembangkan budaya kewirausahaan. Hal ini dilakukan melalui 
program pengembangan diri, pembelajaran kewirausahaan, pelatihan dan seminar wirausaha, program magang ke industri dan usaha, penambahan materi soft skill dan hard skill pada mahasiswa. Selain itu UMS tahun 2000 mendirikan Pusat Inkubator Wirausaha Baru dan bekerjasama dengan LPPM UMS melakukan kegiatan kemitraan dan pelatihan-pelatihan, pengabdian bagi dosen dan mahasiswa yang banyak melibatkan UMKM.

Dari hasil-hasil kegiatan tersebut telah memberikan feed back yang sangat positif terutama menumbuhkan dan mengembangkan jiwa entreupreneurship dikalangan mahasiswa UMS, memberikan pengalaman nyata didunia kerja, membuka kesempatan kerja dan memperkuat hubungan kemitraan UMS dengan UKM.

Permasalahan dalam membangun wirausaha baru mahasiswa dan alumni adalah (1) Kurangnya pendampingan dan permberdayaan bagi mahasiswa dalam membangun mental wirausaha, (2) lemahnya jaringan penjualan dan belum terkoordinasi secara optimal dalam membangun mental wirausaha. Tujuan dan manfaat dalam pengabdian masyarakat ini adalah (a) Menciptakan usaha baru yang mandiri, (b) Meningkatkan soft dan hard skill ketrampilan wirausaha mahasiswa, (c) Membangun peran inkubator kewirausahaan yang cocok bagi mahasiswa PKMK/ mahasiswa wirausaha agar berkembang sebagai unit profit berkelanjutan melalui konsep model dan metode DEFE (Doing, Empowering, Facilitating dan Evaluating)

Suatu negara akan mencapai tingkat kemakmuran apabila jumlah entrepreneur paling sedikit 5\% dari total jumlah penduduknya. Bangsa Indonesia diperkirakan sekitar 0,2\%. Jika diperkirakan bangsa Indonesia penduduknya sebesar 227 juta jiwa, sedikitnya diperlukan 11 juta pengusaha (Astamoen, 2005).
David McClelland seorang pakar entrepreneurship dari Amerika Serikat dan Mitsuyuki Masatsugu seorang konsultan manajemen dari Tokyo Jepang, mengatakan bahwa "kunci membangun bangsa adalah meningkatkan perekonomian bangsa, ditempuh dengan melatih rakyatnya menjadi pengusaha" (Eman Suherman, 2008).

Pemenuhan akan wirausaha tersebut efektif dicapai, jika mampu merencanakan kegiatan pembelajaran kewirausahaan yang terpola dengan baik dan tersusun dalam suatu pedoman dengan tujuan menghasilkan business entrepreneur yang mandiri dan profesional. Pedoman yang aplicable dan implementatif mencapai tujuan pembelajaran kewirausahaan sangat dibutuhkan. Berkaitan dengan hal ini, penulis mengembangkan model dan gagasan inovatif guna menjembatani keharusan dengan kondisi lebih obyektif yang ada sekarang ini.

Secara etimologis, kewirausahaan (entrepreneur) berasal dari kata entrependre (bahasa perancis) atau to undertake (bahasa inggris) yang berarti melakukan. Kewirausahaan bukanlah bakat dari lahir atau milik suku tertentu. Kewirausahaan bukanlah mitos, melainkan realistik atau construct yang dapat dipelajari, dibangun melalui proses pembelajaran, pelatihan, simulasi, dan magang secara intensif (Istiningsih, 2008), (Hubeis. 2009) (Faire. 1973).

Mohanty (2005) "entrepreneurship as the purposeful activity on an individual or group of associated individuals, undertaken to initiate, maintain, or earn profit by production and distribution of economic goods and services", bahwa kewirausahaan sebagai kegiatan yang memiliki tujuan dilakukan oleh individu atau kelompok, dilakukan dengan mengawali, mempertahankan, memperoleh keuntungan dengan produksi dan distribusi berupa barang atau jasa..."entrepreneurs are 
simply those who understand that there is little difference between obstacle and opportunity and are able to turn both to their advantage." (Pinderhughes, 2004). Pengusaha adalah orang yang mengerti sedikit perbedaan antara hambatan, peluang dan merubahnya menjadi sesuatu yang menguntungkan...."entrepreneurship is the alertness to new opportunities", kewirausahaan adalah ketajaman untuk memperoleh peluang/kesempatan yang baru (Audretsch, 2010), (Fayolle. 2006).

Musa Hubeis (2009) mengatakan bahwa inkubasi berasal dari bahasa kedokteran yang berarti proses pematangan dari suatu gejala, tingkat pertumbuhan janin (bayi) di dalam rahim ibunya. Inkubasi diartikan sebagai alat, sarana atau media peningkatan pertumbuhan, nilai manfaat, perkembangan dalam kegiatan penginkubasian.

Merujuk bahasa tersebut, di Rumah Sakit Bersalin, tenaga medis memberi perlakuan berbeda bagi bayi yang terlahir premature dibanding bayi terlahir normal, bayi premature di treatment melalui proses inkubasi. John (2005) menjelaskan "Incubator are generally perceived as a kind of infrastructure geared to support and nurture the establishment and development of small, and medium sized enterprises". Bahwa inkubator bermanfaat sebagai sarana untuk mendukung dan memelihara pembentukan pengembangan Usaha Kecil Menengah (UKM)...."Business incubator are specific entities who support entrepreneurs starting their business lives" (Doris, 2006), inkubator berguna dalam rangka membentuk calon wirausaha baru.

Kemandirian dalam menjalankan usaha dan pemasaran merupakan harapan dan ciri keluaran program inkubator yang mandiri. Keluaran program ini akan memiliki mental tidak menunggu order dari pendamping, tetapi berani menjual sendiri produknya, mampu membuat dan memasarkan produk sendiri, mampu menyelesaikan masalah dengan baik dan berusaha meningkatkan pengetahuan tentang usaha online shop.

Thompson (1993) kemandirian adalah "Independent entrepreneur are intent on creating and developing their own organization and retaining control, as they are more concerned with independence than power", diartikan bahwa wirausaha mandiri menciptakan dan mengembangkan organisasi dan mempertahankan sendiri, karena mereka lebih peduli dengan kebebasan dari pada kekuasaan.

\section{METODE PELAKSANAAN}

Pelaksanaan kegiatan Inwabi, dilakukan dengan tahapan; pelatihan, pemberdayaan, pendampingan dan evaluasi hasil dari para peserta. Lebih detail sebagai berikut:

1. Tahap I

Kegiatan tahap pertama ini adalah: rekruitmen peserta, verifikasi data usaha peserta dan didapat 20 orang peserta, sesuai gambar. 


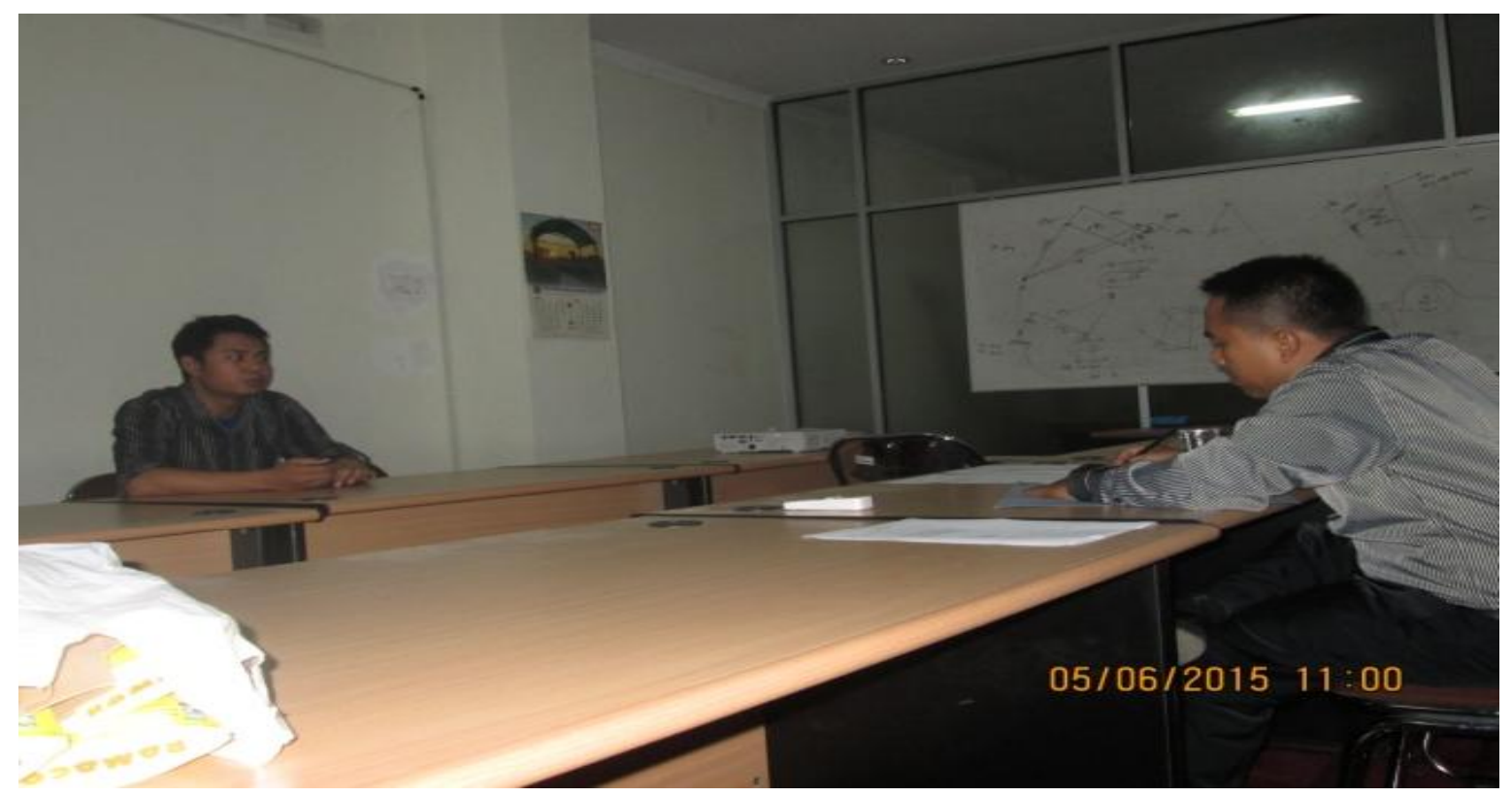

Gambar Rekruitmen Calon Peserta

2. Tahap II

Kegiatan tahap kedua memberikan pemahaman, mindset wirausaha berbasis bakat/potensi. Karakter dan potensi 20 peserta dapat dibaca berdasar finger print dan keakurasian hasil diatas $90 \%$. Materi penyuluhan tentang pengenalan bakat (melalui tes sidik jari), menangkap peluang dan ide bisnis, mengubah bakat menjadi ide bisnis, memahami bahwa ide usaha terbaik bersumber dari potensi bakat, wirausaha berbasis bakat akan menghasilkan 4E (enjoy/gembira, easy/ mudah, excellent/unggul, earn/ produktif).

\section{Tahap III}

Tahap ketiga setiap peserta mempresentasikan usahanya, menganalisis melalui SWOT (Strenght, Weakness, Opportunity, Treath) dari usaha yang dilakukan. Permasalahan yang timbul tersebut menjadi pekerjaan pendamping dan tenant. Tahapan ini membutuhkan keterampilan manajemen (pengelolaan usaha) melalui real business plan. Pendamping memberikan training motivasi dan pengetahuan bisnis serta coaching teknis memulai bisnis. Dilanjutkan magang bagi yang mendalami usaha tertentu agar mampu learning by doing terutama menyusun rencana bisnis. Stimulasi dana muncul pada tahap ketiga dan menjadi permasalahan yang belum bisa terpecahkan secara akurat.

4. Tahap IV

Berdasarkan SWOT analisis yang dipaparkan dari setiap usahanya dilakukan pendampingan dan solusi agar usaha berjalan lebih lancar. Berdasar analisis solusi yang lebih tepat dari permasalahan adalah mempelajari online shop marketing internet, karena lebih dari $50 \%$ peserta mengalami kesulitan bagaimana cara menjual produknya. Baik produk karya sendiri atau karya oranglain tetapi tenant sebagai marketing secara off dan online, sesuai.

\section{Tahap V}

Peserta melakukan pelatihan online shop marketing selama 8 kali di lakukan selama 1,5 bulan. Setiap peserta 
memiliki produk yang dijual dan mampu memanfaatkan social media dengan baik. Mulai dari Facebook, Twitter, Line, Istagram, dll. Penguasaan sosial media sebagai media untuk menjual produknya agar mengalami kenaikan omset penjualan. Selama 8 kali pertemuan diatas $50 \%$ peserta mengakui pentingnya online shop terbukti omset penjualan mengalami kenaikan.

\section{Tahap VI}

Tahap ini digunakan untuk mengobservasi prilaku atau kecenderungan peserta dilihat dan dievaluasi trend omsetnya, apakah mengalami kenaikan, stagnan atau penurunan. Peserta juga membuat komentar, catatn dan hasil akhir kegiatan yang telah dilaksanakan, evaluasi tenant

7. Tahap VII

Peserta di evaluasi melalui berbagai kegiatan yang dilakukan yaitu: membuat real business plan (doing), memulai dan menjalankan usaha miliknya (empowering), pendampingan usaha (facilitating) dan motivasi sukses wirausaha (evaluating).

Akhir dari program inwabi adalah ketercapaian kemandirian usaha (lahirlah wirausaha baru), yaitu mampu menjalankan usaha, membuat produk atau memasarkan. Indikator mandiri memiliki indikasi:

1. Kemampuan teknis usaha, kemampuan teknis memasarkan:
a. mampu mencetuskan tema usaha,
b. mampu menentukan ide-ide pokok usaha,
c. mampu membuat feasibility dan plan usaha;

2. Memiliki kesadaran berwirausaha meliputi beberapa aspek:
a. sadar kebermanfaatan berwirausaha,
b. mengetahui prospek berbisnis/ wirausaha yang dikelola;

3. Memiliki motivasi berusaha atau berbisnis agar selalu maju, meliputi:

a. motivasi membuat usaha,

b. motivasi menjalankan bisnis dan memasarkannya;

4. Mengetahui kelebihan dirinya meliputi:

a. elebihan mental,

b. kelebihan keterampilan berdasarkan potensi bakat;

5. Mengetahui kekurangan dirinya meliputi:

a. kelemahan mental berwirausaha,

b. kekurangan keterampilan;

6. Memiliki kemampuan melakukan akses secara mandiri pada pihak lain, meliputi akses pada:

a. negosiasi dan komunikasi usaha,

b. penguasaan akses peran informasi teknologi,

c. permodalan;

7. Mampu membangun networking pemasaran, meliputi:

a. membuka pasar baru,

b. menjalankan pemasaran;

8. Memiliki modal, harus memiliki modal dalam pemasaran dan modal dalam usaha.

Rencana pengembangan program ini adalah (1) pengembangan dan penciptaan wirausaha mandiri dalam bentuk pelatihan, penempatan mahasiswa ditempat usaha riil dan fasilitasi mahasiswa untuk mandiri. Hal ini akan memberikan sinergi mahasiswa dengan perguruan tinggi, dunia usaha dunia industri, sehingga lahirlah wirausaha baru yang mandiri siap berkompetisi di masyarakat, (2) Sebagai unit profit yang berbasis IPTEKS, (3) menghasilkan wirausaha baru minimal $50 \%$ pertahun dari peserta (tenant), (4) pusat studi wirausaha

\section{HASIL DAN PEMBAHASAN}

Pengambilan data awal diumumkan kepada civitas akademika di UMS sebesar 34.000 dan yang mendaftar 66 mahasiswa 
kemudian dilakukan seleksi dan didapatkan 20 mahasiswa yang terdiri dari 10 mahasiswa yang terdiri dari (10 orang memiliki wirausaha berdasar bakat dan 10 orang berwirausaha tidak memiliki bakat), sesuai tabel-1. Setelah melakukan pelatihan dapat diketahui trend perilaku wirausaha. Dikatakan memiliki mental wirausaha jika peserta memiliki mental usaha mandiri dengan omset penjualan mengalami kenaikan melalui online shop internet marketing.

Tabel-1. Karakteristik peserta inkubator

\begin{tabular}{|c|c|}
\hline \multicolumn{2}{|c|}{ Karakter Wirausaha } \\
\hline Sesuai Bakat & Tidak Sesuai Bakat \\
\hline 10 & 10 \\
\hline
\end{tabular}

Sumber : hasil pengujian data primer (2015)

Ciri peserta yang sukses memiliki mental usaha melalui kegiatan ini memiliki indikasi (a) omset penjualan mengalami kenaikan, (b) kemampuan menjual dengan baik, (c) memiliki jaringan usaha dan membangun akses pada pihak lain.

Tabel 2. Perkembangan Capaian Hasil Mental Usaha

\begin{tabular}{|l|c|c|c|c|c|c|}
\hline \multirow{2}{*}{ Indikator } & \multicolumn{6}{|c|}{ Periode dalam Minggu } \\
\cline { 2 - 7 } & 1 & 2 & 3 & 4 & 5 & 6 \\
\hline $\begin{array}{l}\text { Mental } \\
\text { Wirausaha }\end{array}$ & 2.65 & 2.88 & 3.22 & 3.44 & 3.64 & 3.86 \\
\hline
\end{tabular}

Sumber : hasil pengujian data primer (2015)

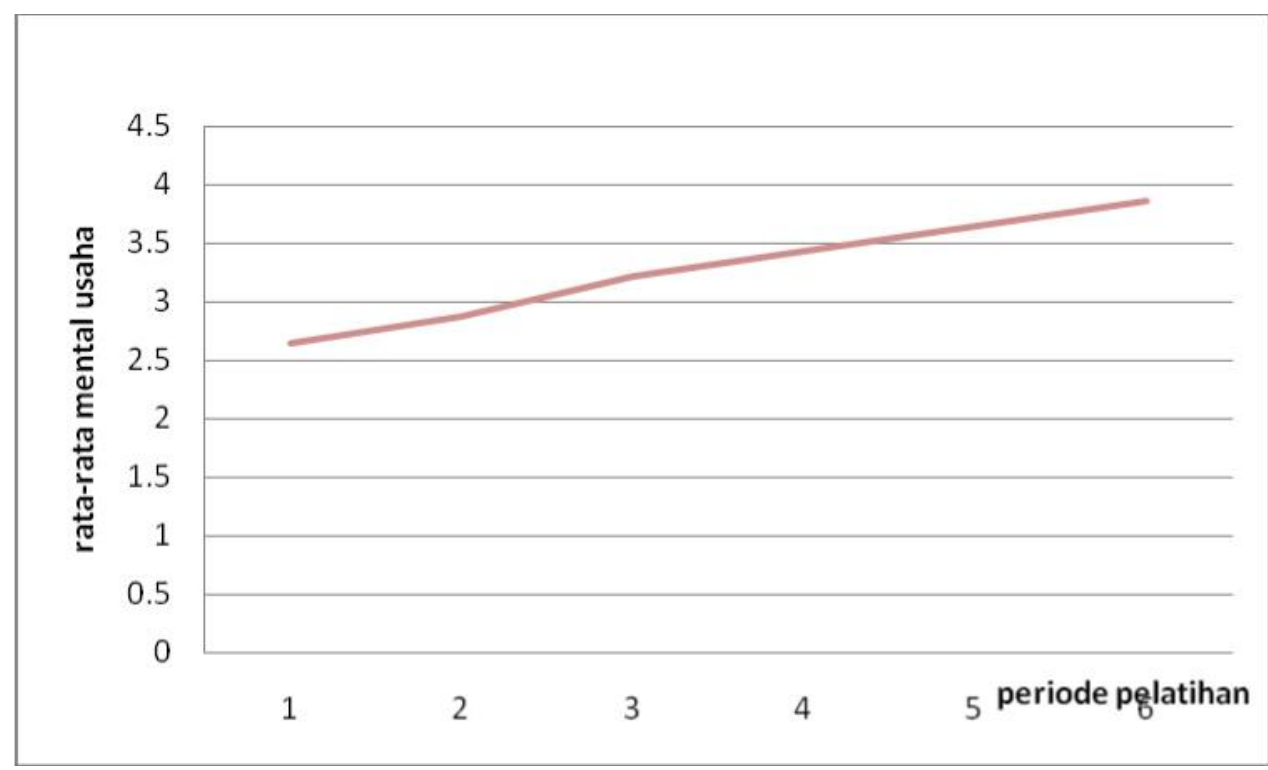

Gambar 1. Perkembangan Capaian Hasil Mental Usaha 


\section{SIMPULAN DAN SARAN}

\section{Simpulan}

a. Program pendampingan melalui inkibator wirausaha berupa pemberdayaan dan pelatihan online shop internet marketing mampu meningkatkan mental wirausaha peserta dan mampu meningkatkan omset penjualan

b. Peran teknologi sosial media yang dikenalkan pada peserta mampu memberikan wawasan dan pengetahuan tersendiri bagi peserta dalam rangka peningkatan hard dan soft skill peserta dan peningkatan omset penjualan

\section{SARAN}

a. Penjualan produk tidak harus membutuhkan modal besar akan tetapi bisa dilakukan melalui penjualan produk pihak lain

b. Pemanfaatan online shop internet marketing dapat digunakan dalam berbagai bidang dalam pemasaran tidak hanya dalam dunia hiburan semata.

c. Program pendampingan inkubator ini tidak hanya berhenti disini, tetapi dapat dilanjutkan pada program pengembangan yang lebaih besar seperti IBK, IBW, IBPE dan lain sebagainya

d. Pemberdayaan dan program pendampingan seperti Ikubator Wirausaha Bisnis perlu pengembangan pada periode berikutnya dan dapat dilakukan setiap 6 bulan sekali (semester)

e. Memaksimalkan peran inkubator kewirausahaan yang cocok bagi mahasiswa PKMK/mahasiswa wirausaha agar berkembang sebagai unit profit berkelanjutan

\section{PERSANTUNAN}

Tulisan ini merupakan artikel publikasi dari kegiatan pengabdian masyarakat bagi mahasiswa yang bergabung dengan inkubator wirausaha bisnis (Iwabi UMS), Kegiatan ini bisa terselaksana dengan baik dan terimakasih kami sampaikan kepada (a) Ketua LPPM UMS, (b) Direktur Sekolah Vokasi UMS, (c) Talent Center Indonesia,(d) Kemal Abdau Internet Marketing, dan seluruh peserta serta pendamping/instruktur wirausaha yang bergabung di Inwabi, (e) Mas Muh Hidayat sebagai administrasi dan siapapun yang terlibat semoga menjadi amal ibadah.

\section{DAFTAR PUSTAKA}

Astamoen. 2005. Entrepreneurship. Alfabeta. Bandung.

Audretsch, David B..2002. Entrepreneurship: determinants and policy in a European-US comparison. Kluwer academic publishers. Massachusetts USA.

Badan Pusat Stastistik. 2011. Laporan presiden republik indonesia. ketenagakerjaan dan pengangguran. Jakarta.

Doris. 2006. E-learning in european smes - observations, analyses \& forecasting. PhysicaVerlag Heidelberg. German.

Eman Suherman. 2008. Desain pembelajaran kewirausahaan. Bandung. PT. Alfabeta.

Faire. 1973. Knowledge-driven entrepreneurship: the key to social and economic transformation. Springer. New York Dordrecht Heidelberg London. 
Fayolle.,Alain. 2006. Handbook of research in entrepreneurship education: international perspectives. Massachusetts Northampton USA. Edward Elgar Publishing Inc.

Istiningsih. 2008. Model pendampingan berbasis among dalam penyuluhan pertanian padi organik di Sleman Yogyakarta. Disertasi doktor, tidak diterbitkan, Universitas Negeri Yogyakarta.

John. P.,Anne Bollintoft, 2005. The networked business incubator-leveraging entrepreneurial agency?.Vol 20. p-267.

Moerdiyanto, dkk. 2010. Program IPteks Bagi Kewirausahaan (Papiku) Universitas NegeriYogyakarta, Artikel Jurnal. Yogyakarta.

Mohanty.,Sangram Keshari. 2005. Fundamentals of entrepreneurship. Prentice-Hall of India Pivate Limited. New Delhi, India.

Muhtadi, 2015. Pengembangan Kewirausahaan Berbasis Program Mahasiswa Wirausaha Di Universitas Muhammadiyah Surakarta, Laporan Pengabdian Masyarakat. LPPM UMS. Surakarta.

Musa Hubeis. 2009. Prospek usaha kecil dalam wadah inkubator. Jakarta. PT. Ghalia Indah. Suherman, Eman. 2008. Desain pembelajaran kewirausahaan. Bandung. PT. Alfabeta.

Pinderhughes.,Paula McCoy. 2004. How to be an entrepreneur and keep your sanity. Amber Books. Boulevard, Suite, Phoenix.

Suranto. 2012. Developing the Entrepreneurship Incubator Model to Increase StudentsIndependence of Entrepreneurship Mentality,. Dissertation. Yogyakarta: Graduate School, Yogyakarta State University.

Thompson. 1973. Quasy experimentation, design and analysis. Chicago. College Publishing Company.

Zimmerer. Zuemm. W. Thomas. Norman M Scarborough. 1996. Entrepreneurship and new venture formation. New Jersey : Prentice Hall International Inc. 